\title{
RESEARCH REGARDING THE INFLUENCE OF COPPER POWDERS ON TENSILE STRENGTH OF SINTERED STEELS
}

Claudiu NICOLICESCU ${ }^{1 a^{*}}$, Daniel ZORILA ${ }^{2 b}$, Victor NICOARA ${ }^{3 c}$, Marco ACTIS GRANDE ${ }^{4 d}$, Marius CRIVEANU ${ }^{5 e}$, Iulian ȘTEFAN ${ }^{6 f}$

\author{
1-3,5,6 University of Craiova, Faculty of Mechanics, Department of Engineering and Management of \\ the Technological Systems, Drobeta Turnu Severin, Romania \\ ${ }^{4}$ Politecnico di Torino, Italy \\ a*nicolicescu_claudiu@yahoo.com, bdan_zorila2000@yahoo.com, cvictorczh@gmail.com, \\ dmarco.actis@polito.it, ${ }^{\mathrm{e}}$ criveanu_marius@yahoo.com, fstefan_iuly@yahoo.com
}

Keywords: sintered steels, carbsint, sintcarb, tensile strength

\begin{abstract}
The aim of this paper is to present experimental results on the evolution of tensile strength of some low alloyed steels function the copper content. There are prepared six types of mixtures as following: A1 (Fe), A2 $(\mathrm{Fe}+1.5 \% \mathrm{Cu}), \mathrm{A} 3(\mathrm{Fe}+3 \% \mathrm{Cu}), \mathrm{A} 4(\mathrm{Fe}+0,2 \% \mathrm{C}), \mathrm{A} 5$ $(\mathrm{Fe}+0,2 \% \mathrm{C}+1.5 \% \mathrm{Cu}), \mathrm{A} 6(\mathrm{Fe}+0,2 \% \mathrm{C}+3 \% \mathrm{Cu})$. All six mixtures were pressed at 400,500 respectively $600 \mathrm{MPa}$ and the green parts were subjected to CARBSINT and SINTCARB thermal treatments. The influence of copper content, pressures and type of thermal treatments on the tensile strength was studied.
\end{abstract}

\section{Introduction}

Sintered steels occupy the largest place on the sintered parts field due to their wide use of these products. Copper is one of the most common alloy elements in the Powder Metallurgy (PM) field [1]. The addition of copper powder to the mixture of iron leads to increased mechanical strength and hardness of the $\mathrm{Fe} / \mathrm{Cu}$ sintered alloys. Generally, $\mathrm{Cu}$ content in the sintered steels is between (1,5-4)\% and improve the tensile strength in the range of $140-240 \mathrm{~N} / \mathrm{mm}^{2}$ [6]. Also, presence of copper in the sintered steels composition has a positive influence on the machining of the sintered parts [2-5]. The present study is focused on the elaboration of sintered steels based on $\mathrm{Fe} / \mathrm{Cu}$ by two types of thermal treatments (CarbSint and SintCarb) respectively on the tensile strength behavior of these steels function the elaboration parameters (compacting pressures, copper content, and thermal treatment)

\section{Materials and experimental procedure}

For the research were used six mixtures based on $\mathrm{Fe}, \mathrm{Cu}, \mathrm{C}$ and $\mathrm{ZnSt}$ as lubricant and the concentration of each mixture is presented in table 1 .

Table 1.

Composition of the mixtures

\begin{tabular}{|c|c|c|c|}
\hline Element & $\begin{array}{c}\mathrm{Fe} \\
{[\%]}\end{array}$ & $\begin{array}{c}\mathrm{Cu} \\
{[\%]}\end{array}$ & $\begin{array}{c}\mathrm{C} \\
{[\%]}\end{array}$ \\
\hline A1 & 100 & - & - \\
\hline A2 & 98.5 & 1.5 & - \\
\hline A3 & 97 & 3 & - \\
\hline A4 & 99.8 & - & 0.2 \\
\hline A5 & 98.3 & 1.5 & 0.2 \\
\hline A6 & 96.8 & 3 & 0.2 \\
\hline
\end{tabular}

*All powder mixtures have been added $\mathrm{ZnSt}$ as lubricant 
All the mixtures were unilateral pressed in a die according MPIF Standard 10 to obtain green specimens for tensile strength respectively rectangular shape in order to calculate the density and porosity of the green specimens. Three pressures as 400, 500 and $600 \mathrm{MPa}$ were used.
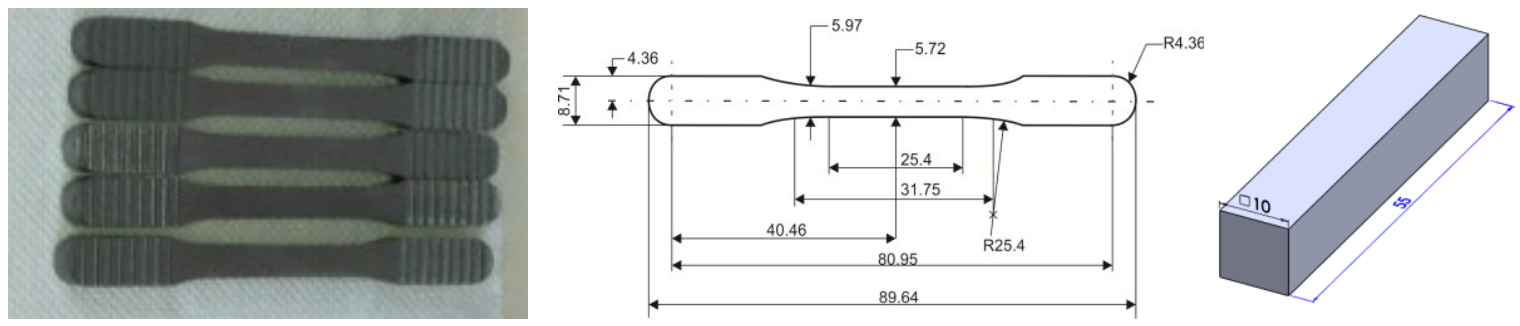

Figure 1. Shape and dimensions of the green specimens

The densities and porosities were calculated with the relation 1, 2 .

$$
\rho=\frac{\mathrm{m}}{\mathrm{v}}\left[\mathrm{g} / \mathrm{cm}^{3}\right]
$$

where: $\mathrm{m}=$ mass of the green part

$\mathrm{v}=$ volume of the green parts

$\mathrm{P}=\left(1-\frac{\rho_{\mathrm{g}}}{\rho_{\mathrm{t}}}\right) * 100[\%]$

where: $\rho_{\mathrm{g}}=$ green density

$$
\rho_{\mathrm{t}}=\text { theoretical density }\left(7,8 \mathrm{~g} / \mathrm{cm}^{3}\right)
$$

In fig. 2 is presented the evolution of the green density and in fig. 3 is presented the evolution of porosity function the compacting pressure and composition of the mixture.

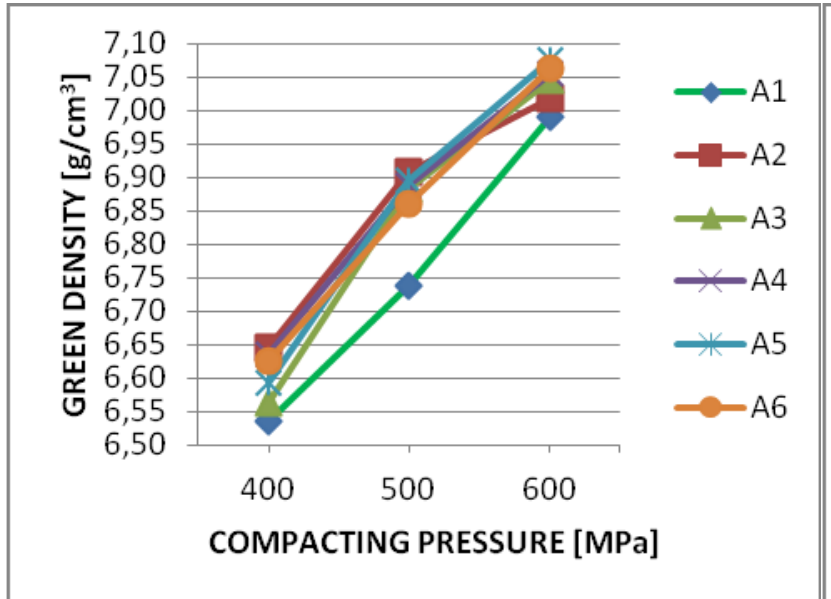

Fig. 2. Evolution of green density

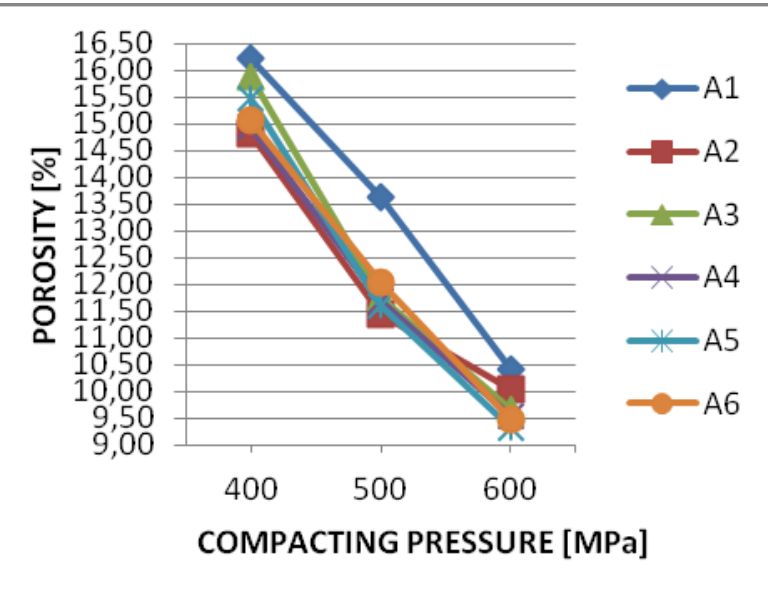

Fig. 3. Evolution of green porosity

According to the graph it is observed that the density increase with the increasing of the compacting pressures and the highest values of density were attained for the mixture A5 pressed at $600 \mathrm{MPa}$.

Porosity being complementary with the density this will decrease with the increasing of the compacting pressure.

The green specimens were subjected to thermal treatments as following:

- The CarbSint (CS) thermal treatment consists in heating up to $910{ }^{\circ} \mathrm{C}$ in argon atmosphere and maintaining at this temperature 45 minutes in $\mathrm{CH}_{4}$ atmosphere (carb) and then heating up to $1150{ }^{\circ} \mathrm{C}$ in argon atmosphere and maintaining for 60 minutes (sint), fig. 4; 


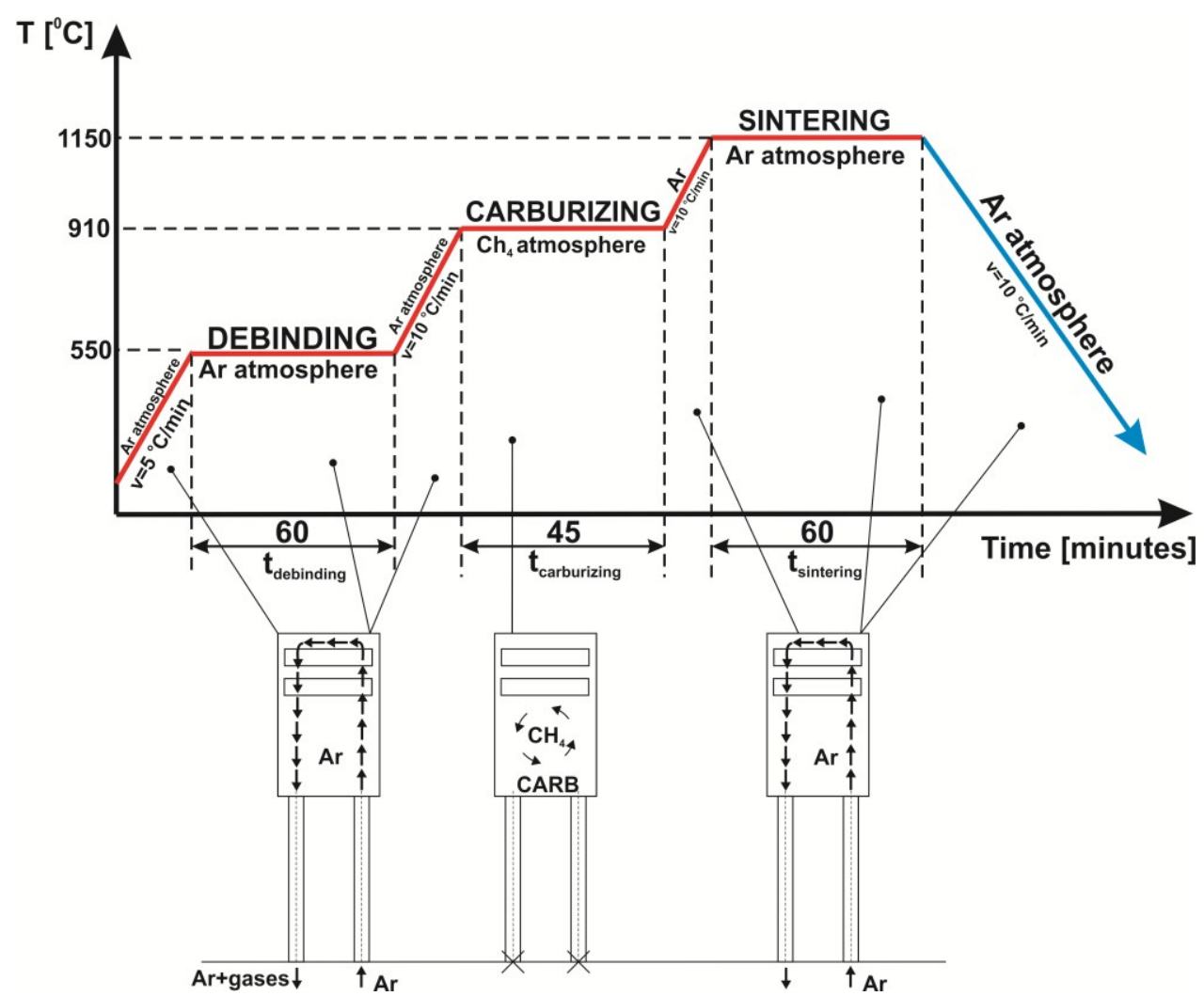

Fig. 4. CarbSint flow chart

- The SintCarb (SC) consists in heating up to $1150{ }^{\circ} \mathrm{C}$ in argon atmosphere, maintaining 60 minutes (sint), after that cooling up to $910{ }^{\circ} \mathrm{C}$ and maintaining for 45 minutes in $\mathrm{CH}_{4}$ atmosphere (carb), fig. 5 .

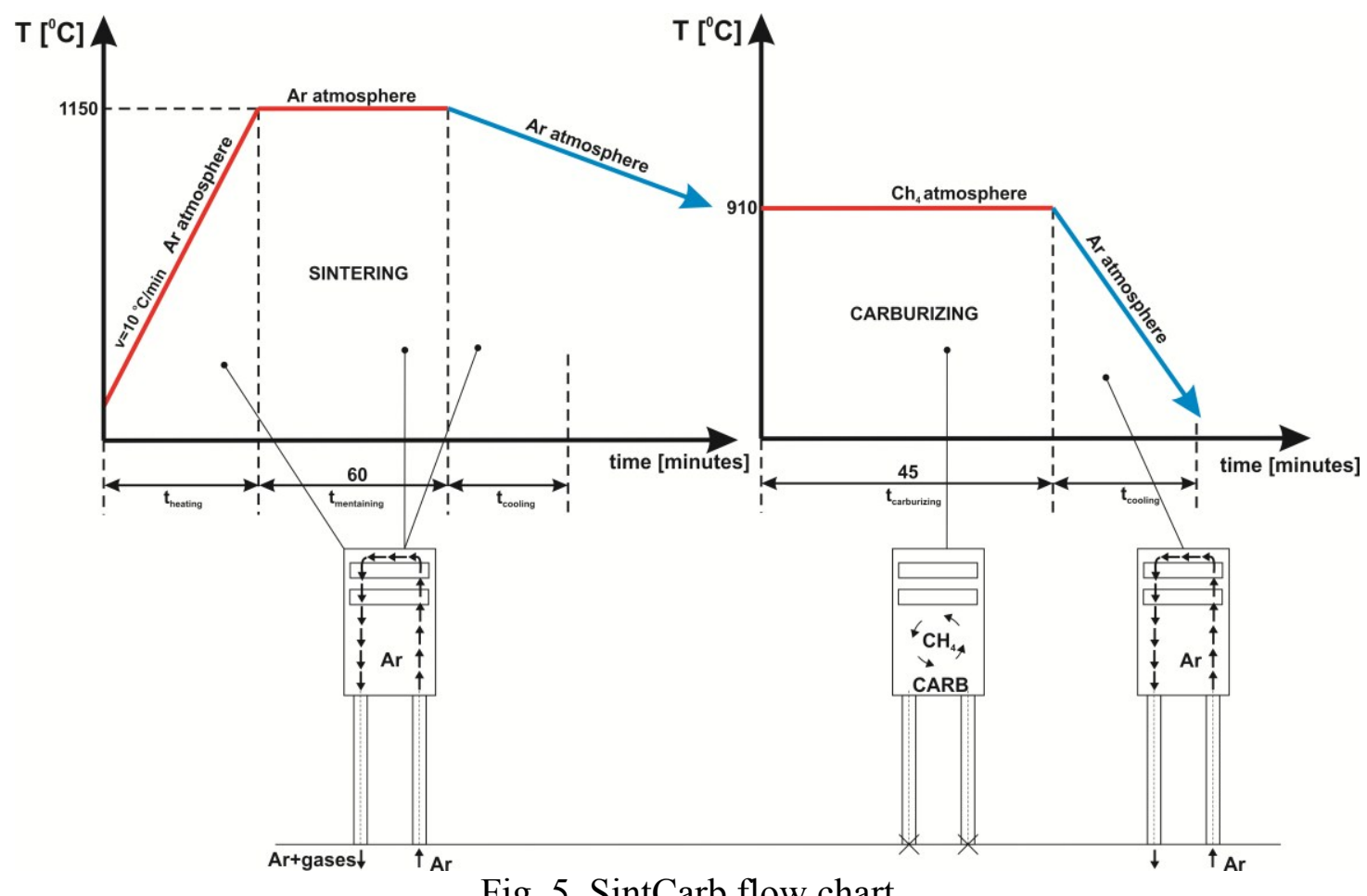

Fig. 5. SintCarb flow chart

For the thermal treatments a Carbolite CWF 1200 oven was used. The samples were placed in a special box in order to ensure the inert gas (Ar) respectively the carburizing gas $\left(\mathrm{CH}_{4}\right)$, fig. 6 . 

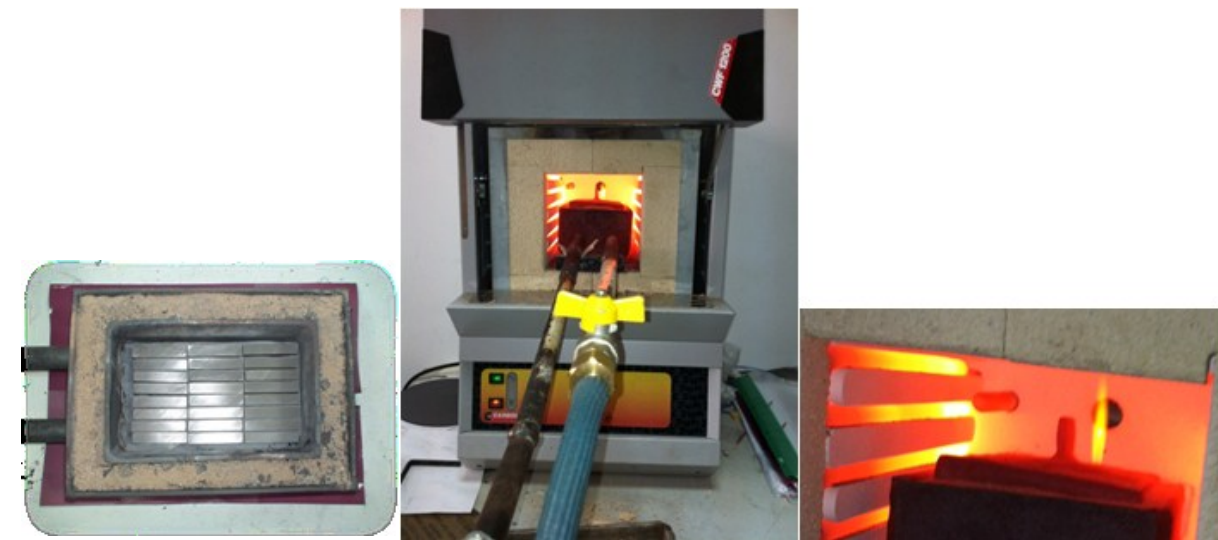

Fig.6. The CS and SC box (left side), the oven with the box inside (center), the carburizing flame (right)

\section{Results and discussion}

After the thermal treatments the samples were encoded as following: A1CS45 - sample obtained from mixture 1 and subjected to CarbSint treatment for 45 minutes; A1SC45 - sample obtained from mixture 1 and subjected to SintCarb treatment for 45 minutes.

In fig. 7-10 are presented the evolutions of the densities and porosities of the samples after thermal treatments.

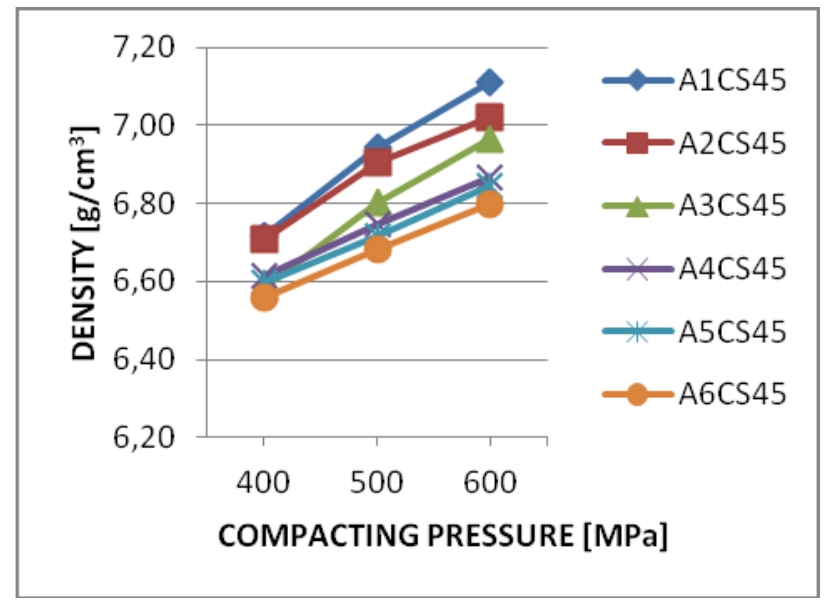

Fig. 7. Evolution of density after CS treatment

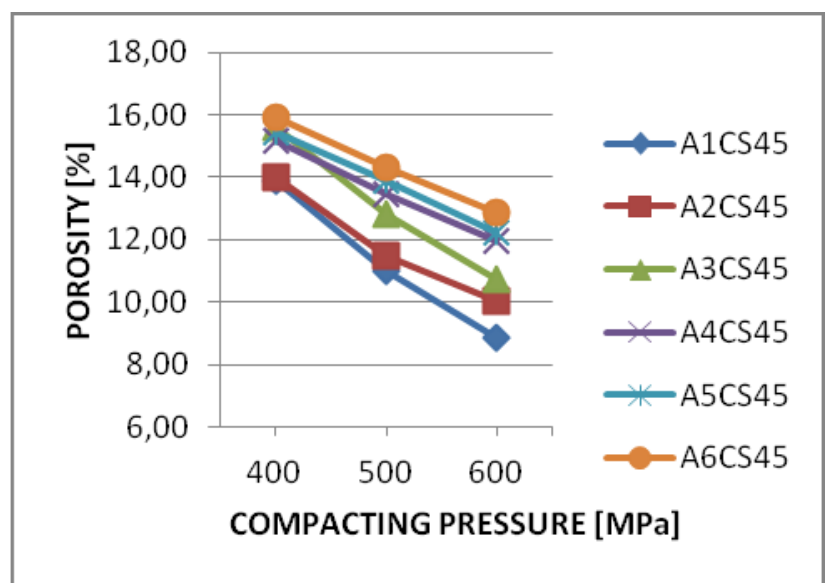

Fig. 9. Evolution of porosity after CS treatment

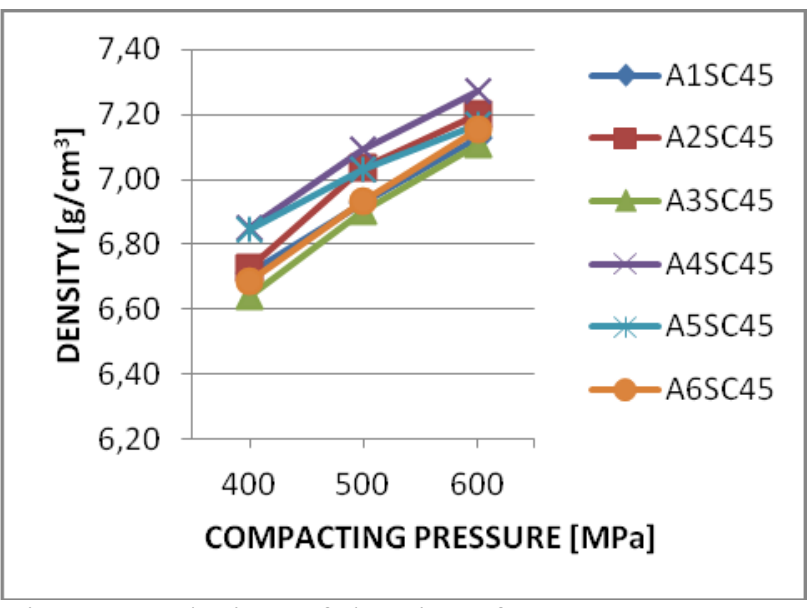

Fig. 8. Evolution of density after SC treatment

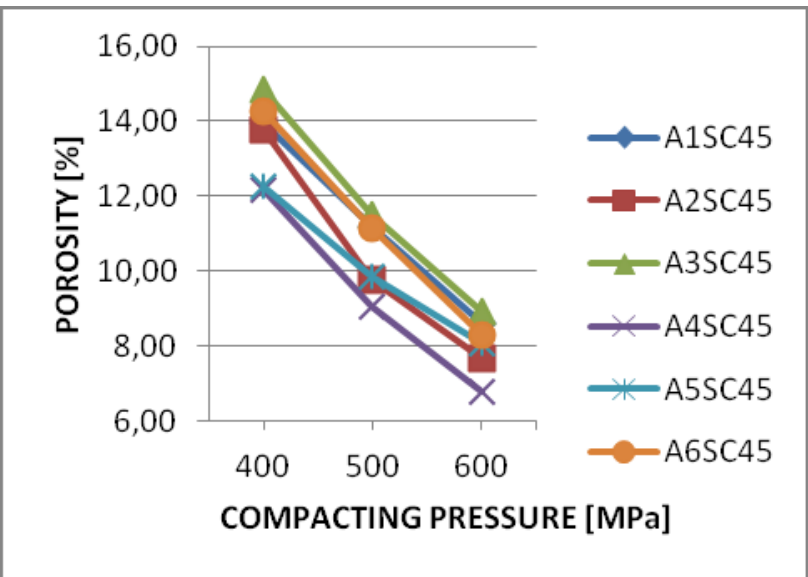

Fig. 10. Evolution of porosity after SC treatment

The highest values for the densities of the sintered steels obtained by CS were attained for the samples A1CS45, A2CS45 respectively A3CS45, these samples not having in their composition 
graphite. Also, the densities increase with the decreasing of copper content and the reason is that, the addition of $\mathrm{Cu}$ promote liquid phase sintering which results in increase in the volume of samples, and thus, the reduction of density.

The sintered steels obtained by SC have the highest values of densities comparative with the steels obtained after CS.

For all the samples were determined the tensile properties: strength (Rm), elongation (A) and maximum force (Fmax) using a LBG machine and the resuls are presented in fig. 11-16.
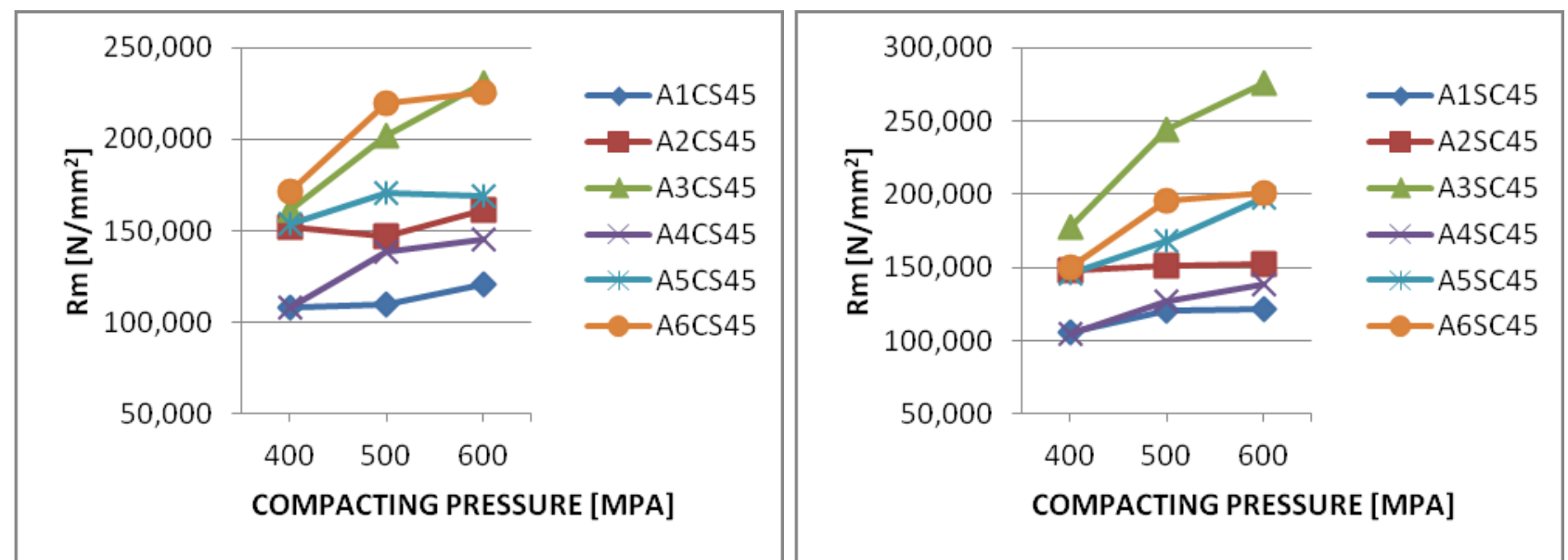

Fig. 11. Evolution of strength after CS treatment Fig. 12. Evolution of strength after SC treatment

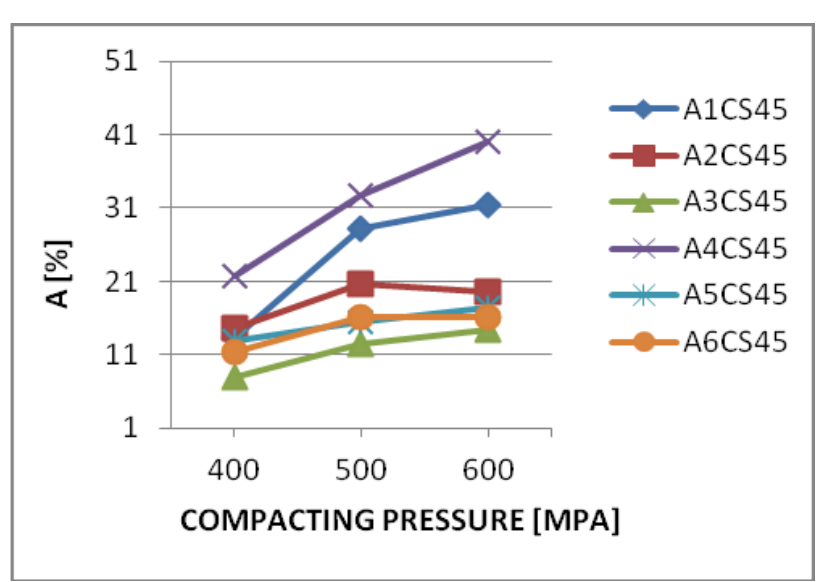

Fig. 13. Evolution of A after CS treatment

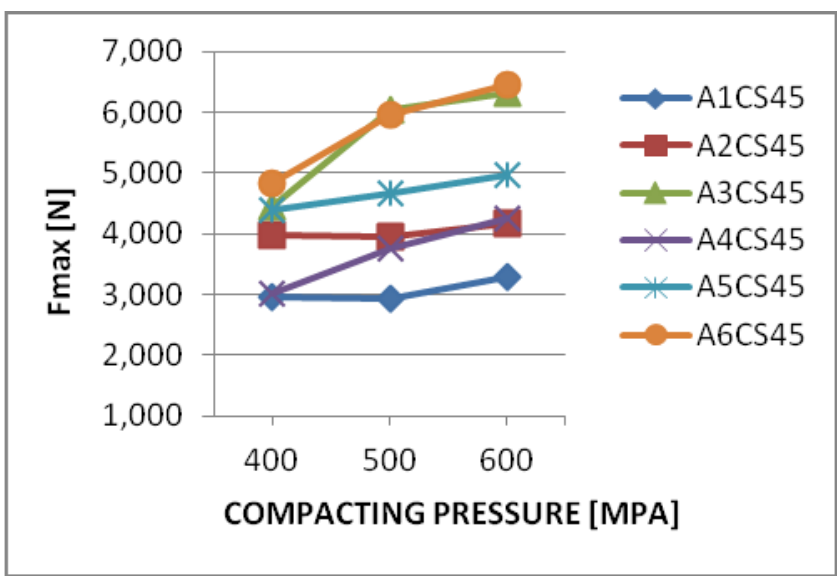

Fig. 15. Evolution of Fmax after CS treatment

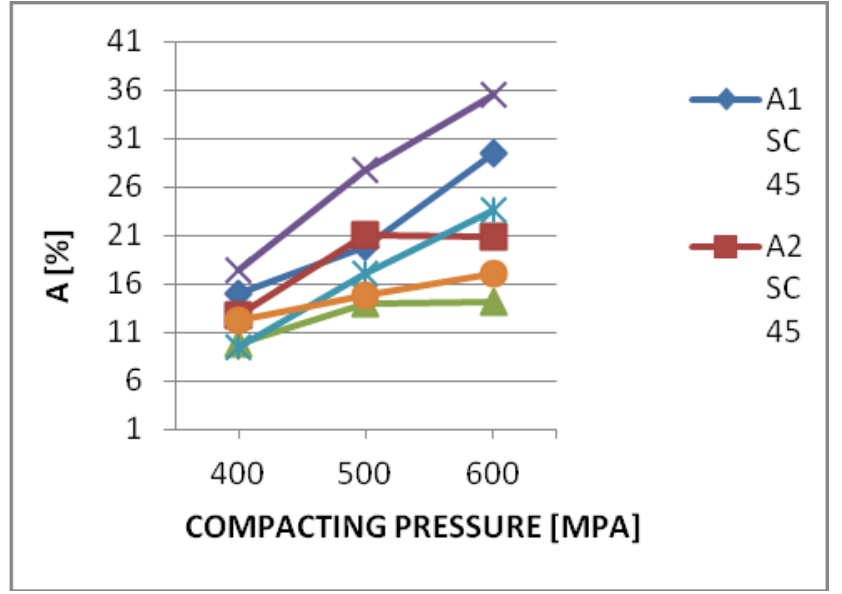

Fig. 14. Evolution of A after SC treatment

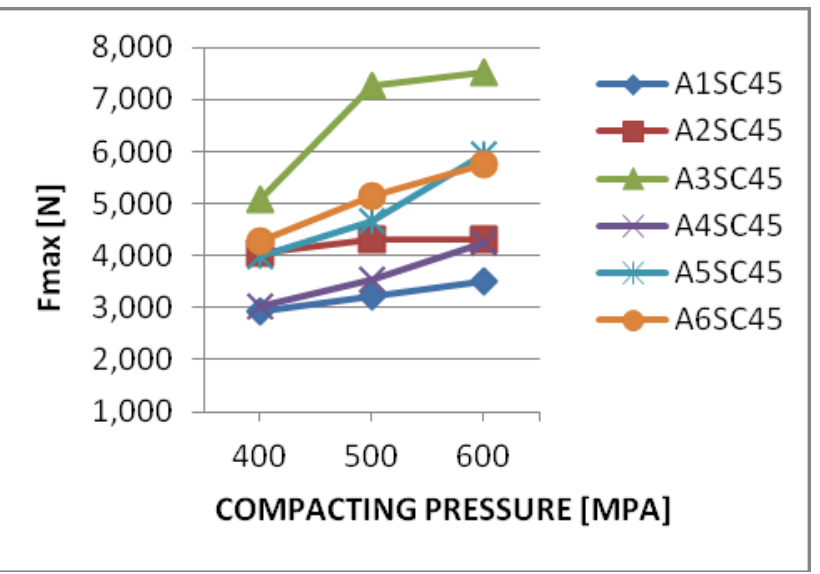

Fig. 16. Evolution of Fmax after SC treatment

According to the graphs presented above the tensile strength parameters of the sintered steels obtained by both treatments (CS and SC) increase with the increasing of the compacting pressures. 
The presence of copper in the steels composition leads to the increasing of strength and the steels with $3 \% \mathrm{Cu}$ in their composition attained the highest values of strength.

\section{Conclusions}

According to the experimental results there can be drawn the following conclusions:

- Copper is an important element for the sintered steels and its presence in the composition of low alloyed steels improve the tensile strength of the material so the highest values for the tensile strength were attained for the samples CS and SC with 3\% copper;

- Tensile strength behavior of carbon steel obtained by CS and SC was studied in comparison with conventional sintered carbon steel. In this context, two types of steels F-0000-15 and F-0000-20 was chosen because they have densities $\left(6,7 \mathrm{~g} / \mathrm{cm}^{3}\right.$ and $\left.7,3 \mathrm{~g} / \mathrm{cm}^{3}\right)$ close to the densities of the sintered steels obtained by CS and SC. According to ASTM B 783-04, these two types of steels have the strength equal to $100 \mathrm{~N} / \mathrm{mm}^{2}$ respectively $140 \mathrm{~N} / \mathrm{mm}^{2}$ which are lower comparative with the values of strength obtained for the steels obtained by CS and SC (105 up to $275 \mathrm{~N} / \mathrm{mm}^{2}$ )

\section{References}

[1] German R.M., ” Powder Metallurgy Science”, MPIF 1994.

[2] I.N. Svinolobova, P.N. Ostrik, A.N. Kovzik,: Properties of iron-cooper master alloy powder. Powder Metallurgy and Metal Ceramics, vol. 36, no. 11-12, 1997.

[3] Mohammad Shadab Siddiqui, Sanjeev Bhargava, Cold compaction and sintering of iron copper mechanically alloyed powder, Proceedings of Ectc, 2008.

[4] Dong Ye, Jun Li, Wen Jiang, Jie Su, Kunyu Zhao, Effect of $\mathrm{Cu}$ addition on microstructure and mechanical properties of $15 \% \mathrm{Cr}$ super martensitic stainless steel, Materials and Design 41, p.1622, 2012.

[5] V.N. Urtsev, D.A. Mirzaev, I.L. Iakovleva, N.A. Tereshchenko, Possibilities of strengthening of $\mathrm{Fe}-\mathrm{Cu}$ alloys upon isothermal aging, Russian Metallurgy, ISSN 0036-0295, no. 4, p. 354-360, 2010.

[6] *** ASTM B 783-04, Standard Specification for Materials for Ferrous Powder Metallurgy $(\mathrm{P} / \mathrm{M})$ Structural Parts 